\title{
The determination of temporal change in land using with satellite images (spot-5,6) in bilecik province of Turkey
}

\begin{abstract}
Remote sensing methods have been used frequently in recent years especially in the monitoring and evaluation of agricultural areas. The use of these technologies is easy to obtain precise information about land use and temporal change. The basic principle used is based on the analysis of the relevant image pixels with the help of a satellite program with specific resolution values or a package program to modify in a certain area with the aid of aerial photographs. It is possible that the classification that is made can be introduced in the result. This research area is aimed to determine the temporal change of land use in Bilecik province of Turkey by satellite images. SPOT 5 satellite images (2010-2013) will be analyzed and the change in land use will be provided by comparing and displaying the SPOT 6 satellite image that provides new attraction in the same region until 2014. In May 2014, a 4-frame SPOT 6 satellite image was provided with the help of the relevant ministry. According to the year 2014, the coordinates of the specific plant and the control points on the earth were taken by GPS and transferred to related software. Finding archives to cover the whole of Bilecik of the Ministry SPOT 5, the classification of satellite images was partially controlled. A controlled classification technique was used for the SPOT 6 satellite image. Relevant land use changes compared to five years between 2010 and 2014, up-to-date land use maps for land change variability have been produced. Classification success, classification success, $93.56 \%$ and kappa values of $0.9386,0.9388 \%$ and 0.9133 , respectively, were found in the year 2010 and in the year 2014, respectively. These rates were $94.23 \%$ and 0.9329 on average, respectively. 94.39 and kappa value of 0.9920 , and land use classification ability was $91.11 \%$ and 0.9300 in the value of the cover value.
\end{abstract}

Keywords: Land Using, Remote Sensing, SPOT 5-6 Satellite Images, Bilecik Province, Turkey
Volume 8 Issue 2 - 2018

\author{
M. Cüneyt Bağdatlı,' İlhan Doran, ${ }^{2}$ Sevinç \\ Adiloglu, ${ }^{3}$ Korkmaz Bellitürk, ${ }^{3}$ Aydın Adiloğlu ${ }^{3}$ \\ 'Department of Biosystem Engineering, Faculty of Engineering \\ and Architecture,University of Nevsehir Haci Bektas Veli,Turkey \\ ${ }^{2}$ Horticulture Department , Faculty of Agriculture and Nature \\ Sciences,University of Bilecik Seyh Edebali, Turkey \\ ${ }^{3}$ Department of Soil Science and Plant Nutrition, , Agriculture \\ Faculty, Namik Kemal University, Tekirdag, Turkey
}

Correspondence: M Cüneyt Bağdatli, University of Nevsehir Haci Bektas Veli, Faculty of Engineering and Architecture, Department of Biosystem Engineering, Nevsehir,Turkey, Tel 90 384228100/I5068, Email cuneytbagdatli@gmail.com

Received: November I, 2017 | Published: March 28, 2018

\section{Introduction}

Land cover / use is one of the main factors that have a significant impact on the natural environment and on the social and economic activities of human beings. It is very important for scientific studies such as multitime, different resolution and land cover data at different scales, natural resource and environment management, co-operation of different disciplines. In addition, it is inevitable that the basic baseline maps obtained from such studies will contribute to the uncovering of agriculture inventory and planning. In particular, the large export of agricultural land in the country greatly increases the importance of land cover maps in planning stages. The current change in the cultivated area and the amount of crops has been reported for many years since it has been determined by general studies conducted. However, this customary method takes more time and is not always reliable. For this reason, the use of new techniques is an absolute necessity for effective land use planning. It is possible to obtain information about other natural resources by establishing such a database covering agricultural areas Tuğaç \& Torunlar. ${ }^{1}$ The rapid growth of the world population, along with the developments in technology, has necessitated more effective research and exploitation of the limited natural resources to meet people's needs. The richness of natural resources is fundamental to economic development and accelerates development. However, the increase in consumption due to economic development has led to a rapid decrease of natural resources. As a result, the use of technology is increasingly playing a role in providing environment and related balances for the identification and use of natural resources. Depending on the development in technology, Remote Sensing Techniques are mostly used in agriculture field. Development in remote sensing and geographic information systems are among the most dynamic elements of the ground surface, such as land cover or land use patterns, the effective use of natural resources, and the primary work needed for rural planning work. In these studies, geographic information systems and remote sensing techniques have high accuracy rate, short study time, low cost at long term etc. is the leading cause of the most used methods in recent years Data collection is often expensive. The temporal and temporal validity of the time-varying data is particularly limited. The rapid change in land management is due to the activities and production of land users. In addition, local knowledge (in the form of a map) is constantly needed in land management studies. From this point of view, it is understood that satellite images providing continuous data from large areas are very effective in revealing land use characteristics (Bronsveld and Chutirattanapan, 1994). Land cover/ use maps serve different disciplines with a wide range of uses. Such maps provide information on a wide range of disciplinary needs, such as land planning studies and locating suitable settlements, removing forestry inventory, monitoring forest health and identifying wildlife, geologists, landslides and erosion areas. Developing countries, rich in natural resources such as Turkey, must orient their planning efforts by revealing these rich potentials in order to strengthen their economies.

The country, which is in the process of accession to the European Community, has to obtain the knowledge of the land cover in the shortest time and in the right direction and form the information bank. 
It is especially important to determine the amount of land cover from satellite images so that direct income support paid to farmers by the Provincial Directorate of Food, Agriculture and Livestock can be determined accurately and up-to-date. In this study, the land cover/use types and temporal changes of the areas within the Bilecik province borders will be analyzed with satellite images. In this context, it was aimed to determine the changes that took place in the land changes with the help of the remote sensing (UA) analysis techniques provided by the Ministry of Food, Agriculture and Livestock and the newly taken SPOT 5 satellite images in 2010, 2011, 2012, 2013 and 2014. The realization of the plans for the future in the region with the realization of this work and the help to make more accurate decisions is very important in terms of the establishment of a database for the current land use in Bilecik province and the fact that the other engineering works to be carried out in this area are the main source for the data.

\section{Materials and methods}

Bilecik is situated in the Marmara region of Turkey between $39^{\circ}$ $39^{\prime}$ 'and $40^{\circ} 31^{\prime}$ ' north latitudes and $29^{\circ} 43$ 'and $30^{\circ} 40^{\prime}$ ' east longitudes. It is the only province that is adjacent to four geographical regions of Turkey. For this reason, it is a transition zone in terms of climate characteristics. Bolu and Eskişehir in the east of the province, Kütahya in the south, Bursa in the west and Sakarya in the north. The area of Bilecik is $4,307 \mathrm{~km}^{2}$. Geographically, the height of the sea is $500 \mathrm{~m}$. of Bilecik; The Gölpazarı, Osmaneli and Sögüt districts are located on the Sakarya River shore, with micro climate climate zones. The location of the Bilecik province on the Turkey map is given in Figure 1. In the study, Spot 5 satellite images were used for the images used in land classification. These satellite views were taken special for this work on May 20 and May 24, 2014. In addition, in order to reveal the temporal change of land use in the study, archives of Spot-5 satellite images of 2010, 2011, 2012, 2013 were used as material in the images.

\section{Method}

In order to determine the distribution of land use conditions and plant species and characteristics, GPS assisted point-taking studies carried out in the field of work in May. These points used in the rectification of the satellite image by the controlled classification operations in the satellite image to be provided with the new date. In addition, a $2.5 \mathrm{~m}$ resolution SPOT 5 satellite image of the zone made in May 2014, and this image presented by the Turkish Ministry of Food, Agriculture and Livestock to be considered for the project. The resulting GPS points and satellite imagery ERDAS Imagine software used to carry out controlled classification of the basin area's land use capabilities and plant classification. In operation, image processing performed in two main stages. These were image enhancement and image classifications. Image enhancement usually involves pre-classification methods. The distinction between features in digital images was called image enhancement Alparslan et al. ${ }^{2}$ by using a variety of algorithms to enhance and better interpret the image. For the purpose of determining land use changes, the main component transformation image enhancement technique used. The data contained in the image are crude and it is necessary to use various statistical analysis and interpretation techniques to transform this seemingly complex data into information. The most common method for converting information into information classifications was image classification. Image classification is the process of generating digital topic maps meaningful from an image dataset. In other words, dividing each pixel in the satellite images into different groups according to their spectral properties and assigning them to the earth corresponding to the pixel reflection values. The image obtained after the classification is called the thematic map. There were two commonly used methods of classification, controlled and uncontrolled classification Erdas Field Guide. ${ }^{3}$ The distribution of vegetation cover in the basin area was revealed by the classification process of Normalized Difference Vegetation Index (NDVI). NDVI was one of the plant indices that determine the amount of vegetation cover Sellers; ${ }^{4}$ Melesse \& Jordan; ${ }^{5}$ Wang et al. ${ }^{6}$ In addition, it removed significantly different lighting features and shadow effects from the sun and perspective Holben \& Frasher; ${ }^{7}$ Shultz et al. ${ }^{8}$ Sotomayor. ${ }^{9}$ Normalized Difference Vegetation Index (NDVI) plants; (R) and near infrared (NIR) $(0.7-1.5 \mu \mathrm{m})$ band between $0,62 \mu \mathrm{m}$ and $7 \mu \mathrm{m}$ was the values determined using reflection values. The red band was insensitive to chlorophyll in plant tissue and the infrared band was sensitive to chlorophyll and therefore reflects higher reflection values Albut et al..$^{10}$ When NDVI was made, the red band will be removed from the infrared band and the value obtained was divided by the sum of the infrared band and the red band.

$$
\mathrm{NDVI}=(\mathrm{NIR}-\mathrm{R}) /(\mathrm{NIR}+\mathrm{R})
$$

Equality; NDVI $=$ Normalized vegetation index NIR $=$ Near Infrared - Near infrared band $(0,76-0,86 \mu \mathrm{m}) \mathrm{R}=\mathrm{Red}-\mathrm{Red}$ band $(0,63-0,69 \mu \mathrm{m})$. The NDVI result values range from- 1 to +1 . The areas where plants gain intensity from these values vary between 0.1 and 0.6 depending on the density and greenness of the plant, while the areas covered by land cover such as clouds, water, snow, and vegetation cover all have negative values. Rocky and soil cover were the same reflection values in the two bands, so they have a value close to zero (Melesse et al., 2003). ${ }^{5}$ According to this, the values between -0.84 and 0.10 in the CNS NDVI are the range of 0.10 to 0.25 value range of rare plant cover (olive and partly plant cover) density while showing the vegetation cover deprived areas and water environments. Frequent and intensive forest cover, vegetation and agricultural areas of the vegetation cover were shown in the range of 0.25 to 0.69 . The NDVI values obtained from Rapideye satellite images was used to determine the vegetation distribution and species characteristics of the basins in the study area.

\section{Processing of satellite data}

Processing of images was the most important phase of the project. Information obtained from satellite or aerial photographs (land cover type, area etc.) was only revealed and evaluated by these methods. Processing of images in project frame; (ERDAS-IMAGINE, ARC/ VIEW, ARC/INFO) and hardware (UNIX and NT Workstations). Single period images of the SPOT 5 satellite purchased within the scope of the project were transferred to ERDAS IMAGINE software so that it can be processed. The following sequence was followed in the processing of images.
a) Clarification of images
b) Geometric correction
c) Classification
d) Image archiving 


\section{New satellite image capture}

SPOT 5 satellite images to be used in the research have frame width of $60 \times 60 \mathrm{~km}$ and terrestrial sampling resolution of $2.5 \mathrm{~m}$. The new satellite image for May 2014 was provided by the Ministry of Food, Agriculture and Livestock. Shooting trajectories and dates for the

Table I New shooting dates for the supplied SPOT 5 satellite image satellites taken in Table 1. Table 2 shows the technical specifications of the SPOT 5 satellites and the position of the satellite satellites taken was given in Figure 2. In addition, examples of raw data of SPOT 5 satellite images taken by the Ministry of Food, Agriculture and Livestock in Bilecik province in 2011 are presented in Fig.

\begin{tabular}{llll}
\hline Area Covered & Shooting Period & Path and trajectory & Shooting Date \\
\hline Bilecik & 1.05 .2014 & Yellow Scene/PathI80 & 20-May-14 \\
& 31.05 .2014 & Yellow Scene/PathI80 & 20-May-14 \\
& & Blue Scene/PathI78 & 26-May-14 \\
\hline & & Blue Scene/Path I78 & 26-May-14 \\
\hline
\end{tabular}

Table 2 SPOT 5 Satellite Image Specifications Subject to Image Classification

\begin{tabular}{llllll}
\hline Satellite & Sensor & Resolution & & \multicolumn{2}{c}{ Strip Width (km) } \\
\hline Spot 5 (CNEC/SPOT) & & Positional $(\mathrm{m})$ & Radimetric (bit) & Trmporarlly (day) \\
& HRS-PAN & 10 & $8 \mathrm{bit}$ & $\mathrm{I}-4(26)$ & 120 \\
& HRG-PAN & $2.5-5$ & $8 \mathrm{bit}$ & $\mathrm{I}-4(26)$ & 60 \\
& HRG & 10 & $8 \mathrm{bit}$ & $\mathrm{I}-4(26)$ & 60 \\
& HRG & 20 & $8 \mathrm{bit}$ & $\mathrm{I}-4(26)$ & 60 \\
\hline & Vegetation & 1000 & $4 / 8 \mathrm{bit}$ & $\mathrm{I}$ & 2250 \\
\hline
\end{tabular}

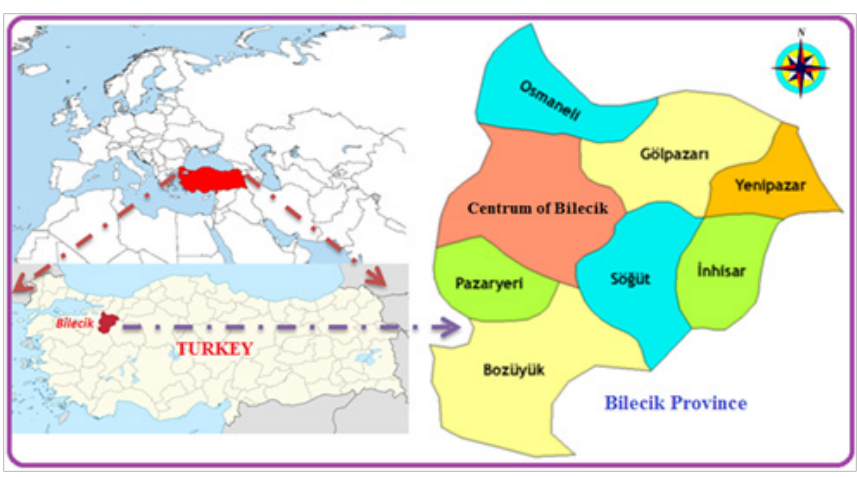

Figure I Location and position of research area.

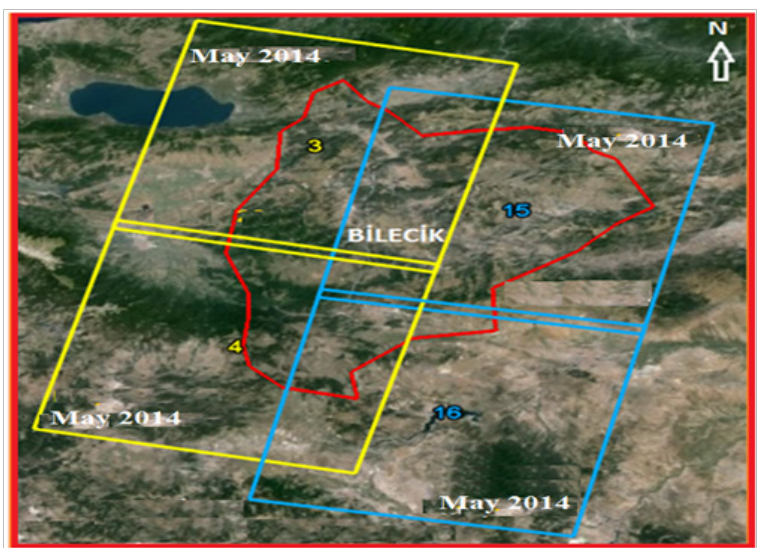

Figure $\mathbf{2}$ Location of the new satellite image to be supplied for the study area according to Bilecik.

\section{Sharpening images}

Satellite images were usually provided as raw images. The sharpness settings of the raw images were not made or were displayed with the fixed values of the image processing software used. For this reason, images sometimes were not providing the necessary clarity. After importing SPOT 6 images and SPOT 5 satellite images obtained from the Ministry of Food, Agriculture and Livestock, ERDAS-IMAGINE software was used to adjust the brightness and contrast settings for those who had sufficient contrast. The histogram equalization method was used to adjust the sharpness of the images used.

\section{Geometric correction}

It had to be based on the world coordinate system so that the satellite images can be evaluated together with maps obtained as a map and the results obtained from the field studies. For this purpose; with the help of ground control points (road junctions, village centers, large buildings, etc.), which we know the actual coordinates, were displayed in real world coordinates with a certain margin of error. During conversion, the average error rates were held to $1.5-2$ image elements (pixels), which correspond to approximately 50-60 meters. Coordinates of the ground control points were determined by global positioning system (GPS) devices within the scope of previous field studies.

\section{Image classification}

Topical and spatial information, which had a significant place in the processing of images, was obtained as a result of the classification process. Therefore, the classification stage was the most important part of image processing. Satellite images with pre-classification sharpness adjustment and geometric correction was cut within the boundaries of 
the relevant province and converted into images only covering that province. Thus, both the work area and the time savings had been achieved. The "Controlled Classification" method was applied in the classification, where the information obtained as a result of the field studies belonging to the region covered by the classification was used. Databases prepared for the field studies were placed on the satellite image belonging to the classification, and sample fields for classification were determined. Then, using the logarithmic functions of these sample fields, the entire image was classified. Maximum Likelihood Algorithm method was used in logarithmic calculations. The process of processing the satellite images was shown in Figure 3 as a flow diagram. The image was obtained at the end of the classification was filtered and a final thematic image was created, continuing between the classes. This was presented in the charts, analyzes and interpretations that show the current types of land cover in the thematic image and their areas with a certain margin of error

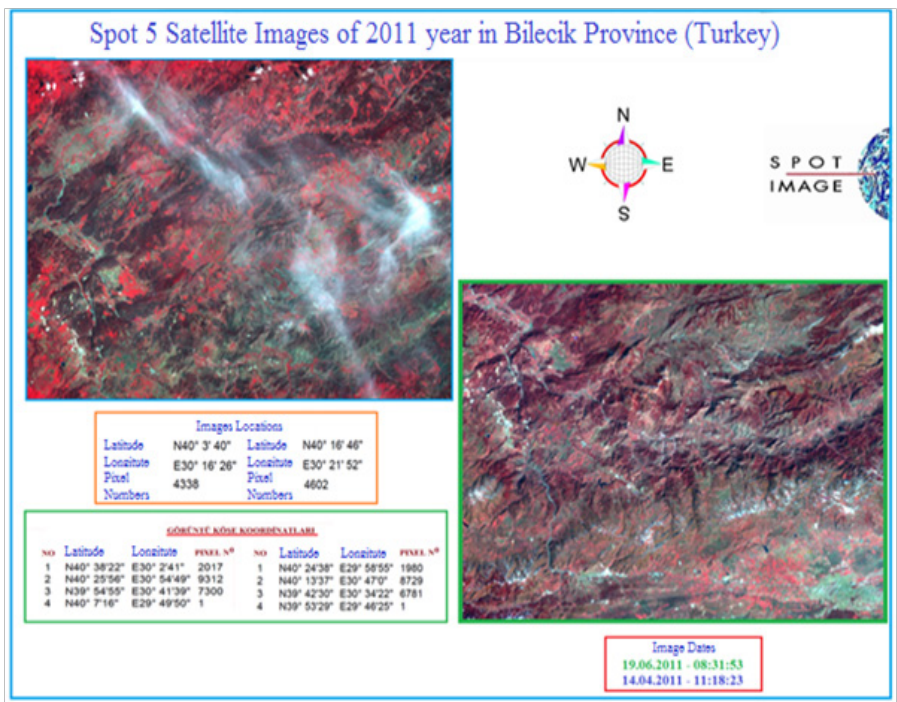

Figure 3 Spot 5 Satellite Images of 20I I year in Bilecik Province (Turkey).

\section{Land studies}

Land studies were crucial for the healthy evaluation of SPOT 5 satellite imagery. Land studies covering the whole of Bilecik province were carried out in May 2014. Coordinate data was provided from the global positioning system (GPS) to be selected by random sampling in order to determine which reflection values corresponded to the satellite images to be obtained regarding the basic components of the land structure. Coordinate acquisition was carried out in terms of the sample in the field studies carried out with GPS support. In this context, some detailed information about the received points were collected and recorded. These;

a. Land covers type (pasture, stubble, fallow, cotton field, corn etc.)

b. Coordinates (as UTM projection)

c. Altitude (in meters)

d. Date and time of receipt

e. Coordinate photograph of point

f. The pitch of the receiving point

\section{Research findings}

\section{Rectification of satellite images}

In order was be able to rectify satellite images, coordination works were carried out for 5 days in May $2015^{11}$ from DGPS devices on satellites. 41 ground control points had been identified in this context. The obtained coordinate values were given in Table 3 and the image about the field works were given in Fig. In addition, some points related to the ground control points on satellite images were given in Figure 4 \& Figure 5.

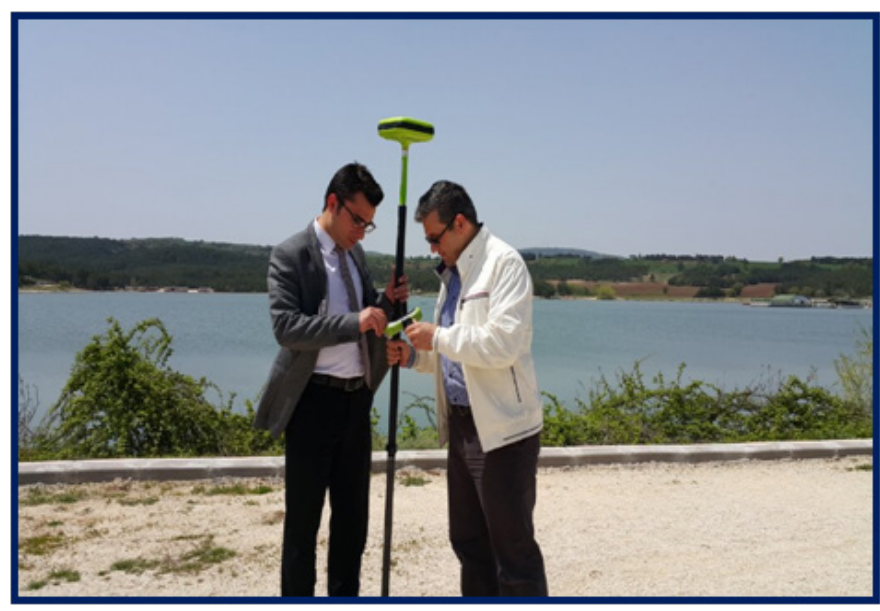

Figure 4 Coordinate work to determine the ground control points.

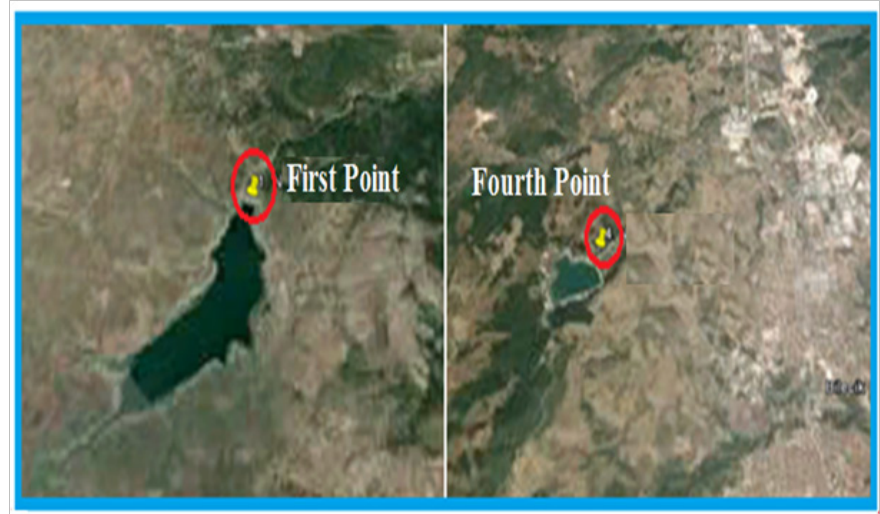

Figure $\mathbf{5}$ Some application views for the specified ground control points.

\section{Collection of sampling points for controlled} classification

In order to perform controlled classification via satellite images, the collection of control points were carried out taking into consideration the periods of growth, growth and growth of agricultural products and taking into account the date on which the new dated (2014) SPOT-6 satellite images were taken. In this context, in May 2014, a field study was carried out in Bilecik province in order to collect floor control points related to different product designs, and coordinate values from 108 different points were taken and these points were photographed.

\section{The analysis results of satellite images}

Classification success as a result of controlled classification based on land use classification of years of satellite images were found as 
93.56\% and kappa value of 0.9386 on average, $94.33 \%$ for closure and 0.9368 for kappa value, $91.33 \%$ for land use classification and 0.9133 for kappa value, respectively. In 2011, these ratios were found as $91.12 \%$ and 0.9141 on average, $90.33 \%$ for closure, 0.9078 for kappa value, $90.31 \%$ for land use classification and 0.9032 for land use classification, respectively. In 2012, these ratios were $90.12 \%$ and 0.9430 on average, respectively, with a classification success of $90.30 \%$ for closure and 0.9110 for kappa value, $90.13 \%$ for land use classification and 0.9125 for land use classification. In 2013, these ratios were $94.10 \%$ on average and 0.9129 on the cover, $91.29 \%$ on classification for closure, 0.9405 on kappa value, $90.19 \%$ on land use classification and 0.9204 on land cover classification. In 2014, these ratios were $94.23 \%$ and 0.9329 on average, respectively, with a classification success of $94.39 \%$ for closure, 0.9920 for kappa value, $91.11 \%$ for land use classification and 0.9300 for land use classification. Since the resolutions of the SPOT 5 and SPOT 6 satellite images was low, the ground control points detailed in Annex-1 could not be categorized and the satellite images were displayed under 8 main classes. Water surfaces, Fallow Fields, Empty Fields, Cultivated Agricultural Fields, Meadow and Pasture Fields, Settlements, forests, marsh-reed areas. Bilecik province 2010-2014 land use situation was realized by using controlled classification technique over SPOT 5 satellite images under 8 classes. Although it was not possible to classify the past years as visually-controlled, it was possible that certain fixed areas such as water surfaces, settlements, forests, fruit gardens, vineyards and vegetable fields were interviewed by individual farmers and the responses of the agricultural production in the relevant area in 2010, could be realized on satellite images provided within. However, in 2014, the SPOT 6 satellite images were renewed during the period in which the project was underway, and during this period, land works were carried out parallel to this same period, and the reference points were collected and the SPOT 6 satellite images were applied in 2014. In the scope of the study, a digital elevation model including the whole of Bilecik obtained from satellite images was also created and the model image obtained is given in Figure 6. In Figures 7-11 the map shows the land use status obtained as a result of the controlled classification on the Spot 5 satellite images provided for Bilecik during 2010-2014. ${ }^{12-14}$

Table 3 Coordinates of the ground control points used for the purpose of classification

\begin{tabular}{lll}
\hline Point Numbers & $\mathbf{X}$ & $\mathbf{Y}$ \\
\hline $\mathrm{I}$ & 39.793 & 29.965 \\
2 & 39.927 & 29.983 \\
3 & 40.033 & 30.024 \\
4 & 40.162 & 29.945 \\
5 & 39.894 & 29.953 \\
$\ldots \ldots$ & $\ldots \ldots$ & $\ldots \ldots$ \\
38 & 30.799 & 29.795 \\
39 & 40.039 & 30.201 \\
40 & 39.853 & 30.242 \\
\hline 41 & 39.879 & 30.227 \\
\hline
\end{tabular}

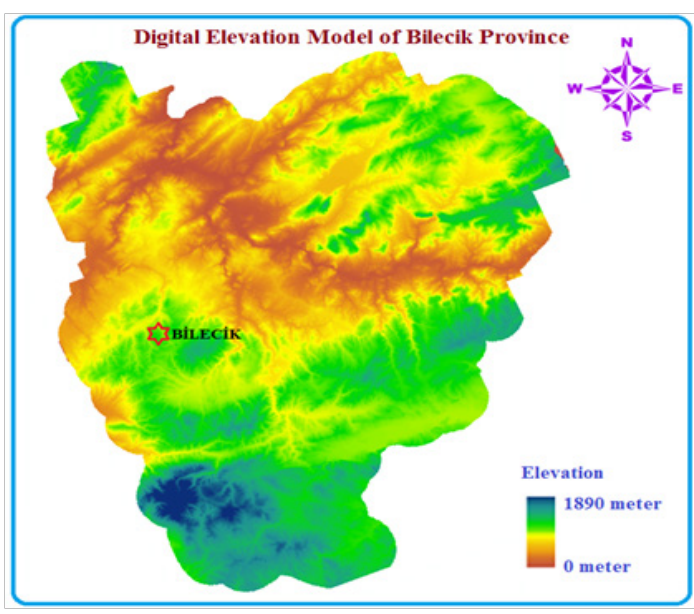

Figure 6 Digital Elevation Model of Bilecik Province.

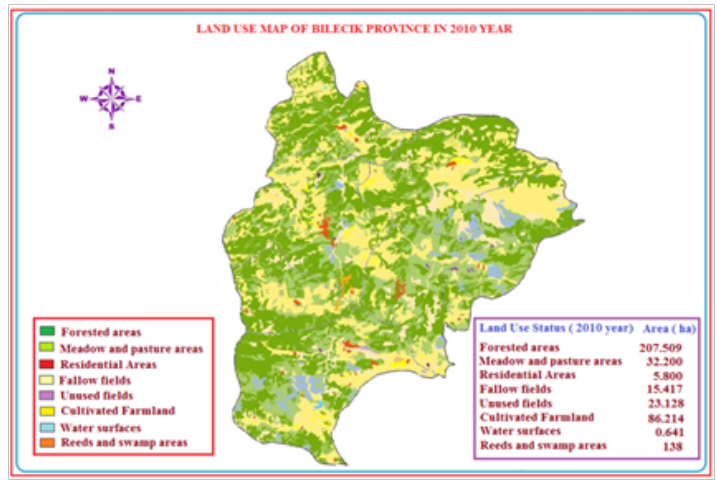

Figure 7 Land Using Map of Bilecik Province in 2010 year.

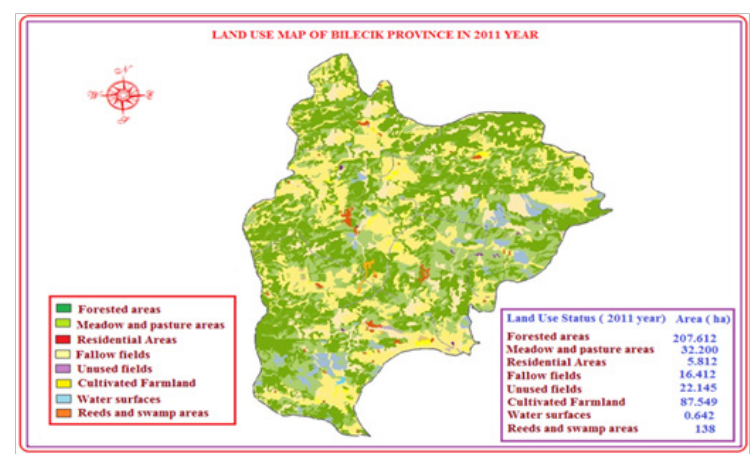

Figure 8 Land Using Map of Bilecik Province in 2011 year.

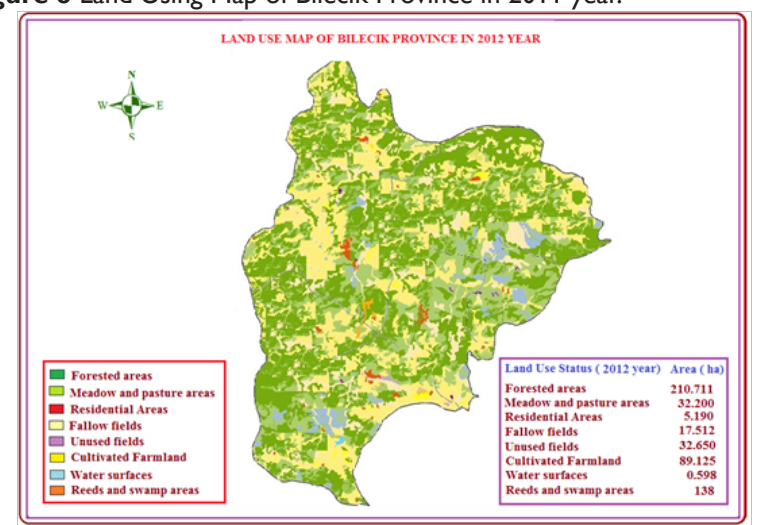

Figure 9 Land Using Map of Bilecik Province in 2012 year. 


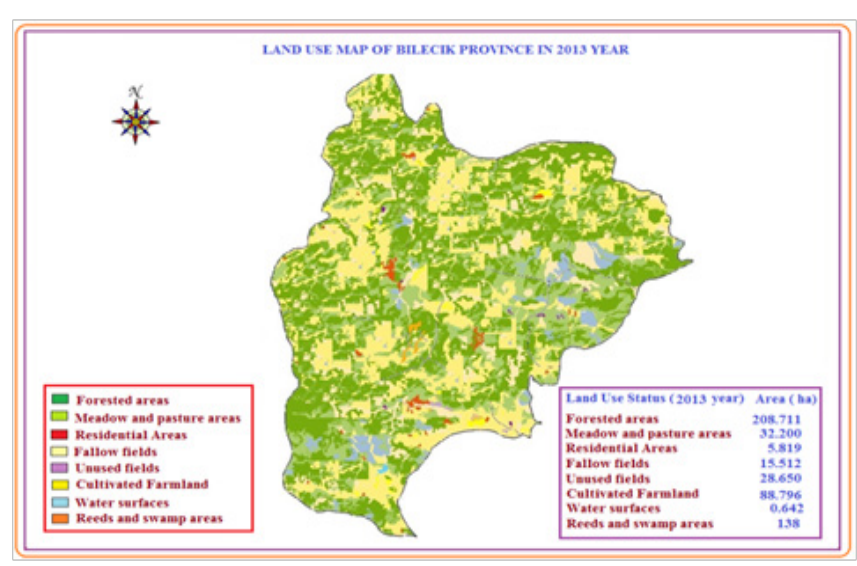

Figure I 0 Land Using Map of Bilecik Province in 2013 year.

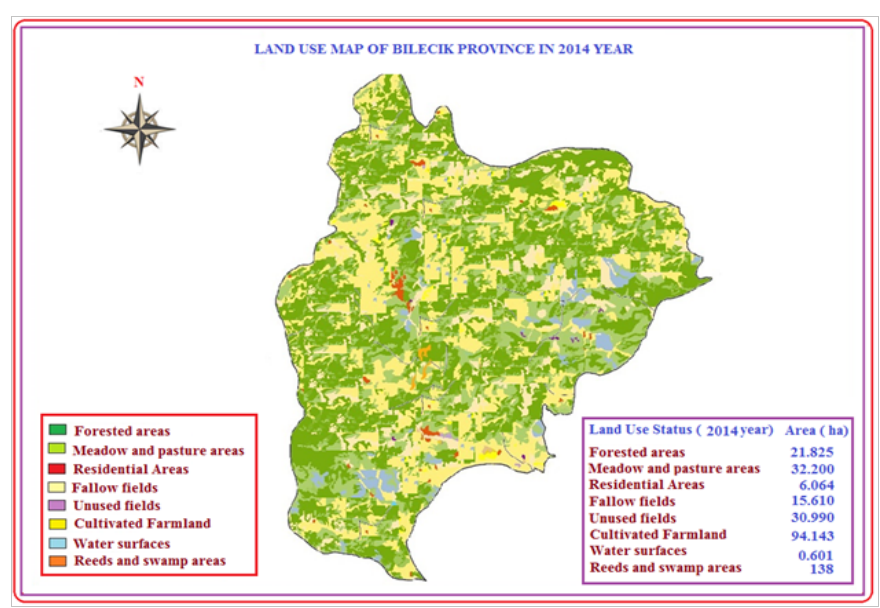

Figure I I Land Using Map of Bilecik Province in 2014 year.

\section{Recommendations}

Determination of land use abilities is of utmost importance in the context of all infrastructure works. The fact that the land use is made based on years has important implications for following the course of the change. All kinds of work can be directed by following the course of the change of years. However, the quality of the satellite images and the high resolution will lead to the high accuracy of the resulting results. In this study, Bilecik province's SPOT 5 and SPOT 6 satellite images provided by the Ministry of Food, Agriculture and Animal Husbandry were used to show the land use situation between 2011-2014 years. As the resolution of the related images is low, the number of classifications related to land use has to be limited. The limitation of the project budget and the fact that the cloudiness rates of the satellite images in the study are partly high at some points has also directly affected the analysis result. However, analysis of constructions showed that kappa statistic values were at $90 \%$ levels on a pixel basis. This suggests that the results are usable. As a result of the analyzes made via satellite images, land use change between 2010 and 2014 was found to be the increase in artificial regions and decrease in agricultural areas. No change in water masses was observed when a decrease was observed in forest location and semi-natural areas. In addition, the increase in the amount of new construction is a sign of new construction in the city. Although the economy of the province has been reduced to agricultural land due to the opening of the agricultural land, the agricultural land has been reduced. Apart from these, both needles and broad-leaved forests have been declining, but new forestation areas have been trying to ensure the continuity of the forests. In the results of working; related land use changes Compared to five years between 2010 and 2014, up-to-date land use maps for land change were generated. This work, which is very important in terms of ensuring agricultural sustainability in the region, will provide positive contributions especially in preventing misuse in agriculture and forest areas. It will be inevitable that the obtained data will be shared by the Ministry of Food, Agriculture and Livestock Bilecik Provincial Directorate and Special Provincial Administration and Municipalities and infrastructure support will be provided to relevant stakeholders for all planning studies.

\section{Acknowledgment}

This study was supported Bilecik Seyh Edebali University, Scientfic Research projects, Project Number: 2014-01.BIL.14-02

\section{Conflict of interest}

None.

\section{Reference}

1. Tuğaç MG, Torunlar H, Peşkircioğlu M, et al. Establishment of Agricultural Database by Using Geographic Information Systems Techniques and Land Use Planning Yapılması, 2000.

2. Alparslan E, Dönertas A, ve Yüce H. Analysis of the Changes in Yalova! Li Coastal Settlements from Satellite Images,3. Geographical Information Systems, Bilisim Günleri Bildiriler Kitabı, Fatih University, Istanbul, 2004.

3. Erdas Field Guide. Second Edition Erdas Inc., Atlanta, 2003,USA.

4. Sellers PJ. Canopy Reflectance, Photosynthesis and Transpiration. Int J Remote Sensing.1985;6(8):1335-1372.

5. Melesse AM, Jordan JM. Spatially Distributed Watershed Mapping and Modelling: Thermal Maps and Vegetation Indices to Enhance Land Cover and Surface Microclimate Mapping: Part 1, Journal of Spatial Hydrology. 2003;3(2).

6. Wang Q, Tenhunen JD. Vegetation Mapping with Multitemporal NDVI in North Eastern China Transect (NECT)", International Journal of Applied Earth Observation and Geoinformation. 2004;6(1):17-31.

7. Holben BN, Fraser RS. Red and Near Infrared Response to Off Nadir Viewing, International Journal of Remote Sensing. 1984; 5(1):145-160.

8. Schultz GA, Engman ET. Remote Sensing in Hydrology and Water Management, Germany, Springers. 2000;230:539-540.

9. Sotomayor AIT. A Spatial Analysis of Different Forest Cover Types Using GIS and Remote Sensing Techniques; A Case study in Shivapuri Area, Nepal, Master of Science Thesis, ITC, 2002; Netherland.

10. Albut S, Uysal T. Investigation of the Change of Vineyard Areas in Tekirdağ Basin over the Years and Determination of New Top Vineyard Areas in Tekirdağ-Șarköy Province by Using Geographical Information Systems (GIS) Symposium on Viticulture and Techniques in Turkey,Manisa. 2009. 
11. Anonim. Bilecik is a long-term average climate data. 2015.

12. Anonymous TC. Bilecik Governorship, Provincial Directorate of Environment and Urbanism, 2013. Yll Bilecik Environmental Situation Report, Bilecik. 2014.
13. Aronoff S. Geographic Information Systems: A Management Perspective, 1989,Kanada.

14. TÜIK,

http://www.tuik.gov.tr/PreTabloArama. do?metod=search\&araType=vt Tarih: 2015;30(6). 